\title{
Reconstruction of an architectural object. Case study: Citadel fort No. 33 "Krakus" in Krakow
}

\author{
Izabela Piech $^{1, *}$, Boguslawa Kwoczynska ${ }^{1}$, and Artur Ciszewski ${ }^{2}$ \\ ${ }^{1}$ University of Agriculture in Krakow, Faculty of Environmental Engineering and Land Surveying, Poland \\ ${ }^{2}$ Graduate of the University of Agriculture in Krakow, Poland
}

\begin{abstract}
The aim of the study was to recreate, in the form of a 3D model, the Citadel fort No. 33 "Krakus" in Krakow. The data on the basis of which the three-dimensional model was made were obtained using a Leica ScanStation P40 terrestrial laser scanner, which is owned by the Faculty of Environmental Engineering and Geodesy of the University of Agriculture Hugona Kollataj in Krakow. The scope of field work included performing laser measurements, and then processing the point cloud in the Leica Cyclone 3D program and creating a full architectural model in SketchUp 2016.
\end{abstract}

\section{Introduction}

Photogrammetry is now used in many areas of life [1]. Thanks to it, we deal with a wide range of methods and devices that enable obtaining precise data about the world around us. Particularly noteworthy are the very popular satellite techniques and laser scanning, which is among others the subject of this study [2,3]. Due to the simplicity of operation and high precision of measurement, laser scanning has become an extremely valuable tool, applicable in many areas of life $[4,5,6,7]$. One of the areas that has gained completely new opportunities thanks to laser scanning is architecture $[8,9,10,11]$. The methods and devices used in this technology proved to be extremely useful at the stage related to the design, construction, inventory and reconstruction of the architectural object $[12,13,14]$. The proof of this is e.g. creating three-dimensional models based on the point cloud obtained using terrestrial laser scanners [15]. Laser scanning is an active system of data acquisition, thanks to which it is possible to precisely determine the shape and mutual geometrical relations between objects in the scope of the scanner [16]. Thanks to this, it is possible to obtain any views, projections and sections based on once recorded data, perform analyzes for any place of the object as such needs arise, easily repeat measurements, compare them and present results [17].

Scanning technology is currently one of the fastest growing technologies on the market. Many years have passed since the introduction of the first laser scanner and this technology has found its application in various industries. The interest in this subject is still growing. Technological development means that 3D scanners are systematically improved, which directly affects the extension of areas in which they can be used: from surveying and industrial surveys, through medicine, forestry, forensics and many others [15]. Laser scanning allows the measurement of both giant terrain by measuring measurements from the terrestrial orbit (Satellite Laser Scanning - SLS) or using scanners mounted in aircraft (Aviation Laser Scanning - ALS) through smaller linear objects (Mobile Laser Scanning English. MLS) or point (Terrestrial Laser Scanning called TLS) to quite small, several-dozen-centimeter objects. Data obtained in the results of laser measurements can be used for various types of analyzes, records, inventory. This technology is applicable not only in geodesy, but also in many related areas such as real estate management and spatial planning. It is also used in architecture (inventory of monuments), civil engineering or even in the investigation of car accidents (examination of car body deformations).

\section{Research work}

The aim of the study was an attempt to recreate, in the form of a 3D model, the Citadel fort No. 33 "Krakus" in Krakow. It was built as part of the popular then, derived from the German school, polygonal system of building forts. It essentially consisted in applying in the defense premises of a caponier and straight or broken walls. However, it must be noted that the Krakus fort has an eclectic form, therefore, instead of a fairly general term "citadel", it should be described as a transitional fort, between a redoubted fort and a centered one. The first one was characterized by a reduit, that is, the object of the circumference intended for the artillery placed on the foreground of the defensive line, while the centered fort had all the battle stations combined with each other. (Fig.1).

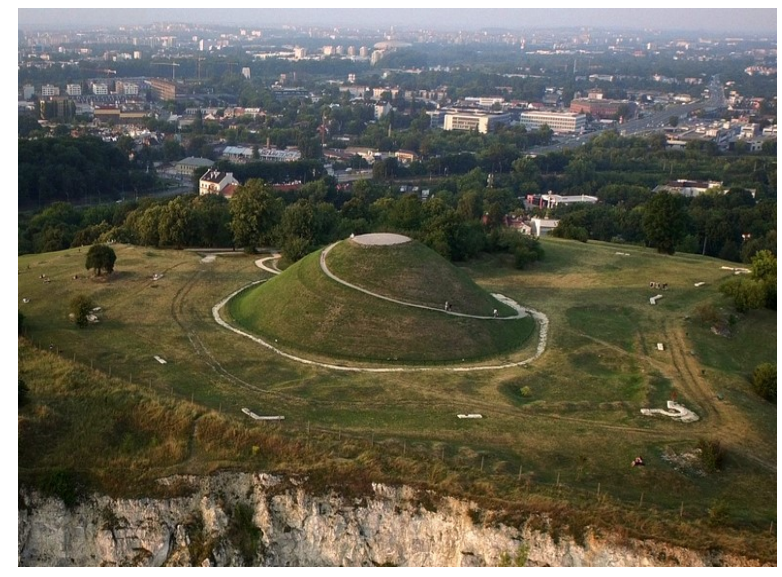

Fig. 1. Krak's mound and ruins of the fort - today's state.

\footnotetext{
* Corresponding author: rmpiech@cyf-kr.edu.pl
} 
The Krakus Fort is different because instead of the classical reduit, it possessed the so-called "neck barracks" at the entrance to the facility (Fig.2).

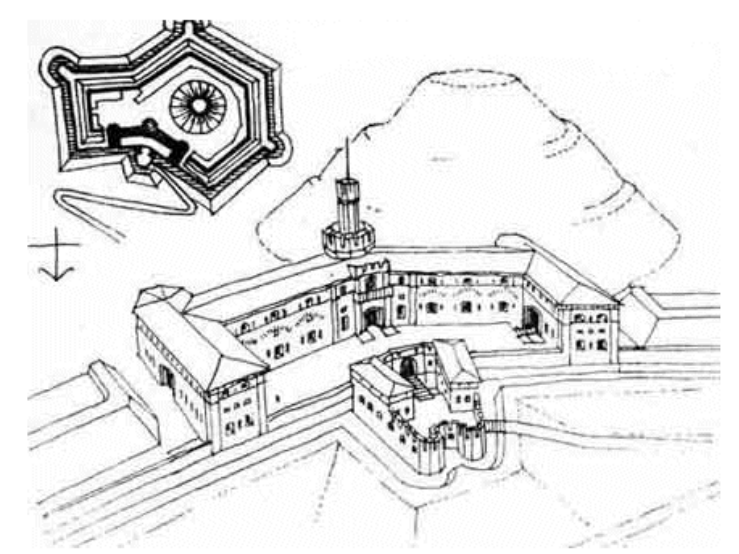

Fig. 2. Neck barracks used in Krakus fort.

Built in the neo-Gothic style, it had the shape of an irregular octagon composed of two connected figures: hexagon around the mound and adjacent quadrangle (Fig.3). There were three caponiers in the defensive circuit reinforced by the embankment, while in the neck of the establishment the neck caponier and already mentioned two-storey U-shaped neck barracks. They were topped with a characteristic two-part tower, reminiscent of old English castles [3]. In terms of building material, fort no. 33 was no different from other forts in Krakow. The basic materials were wood, earth and brick and stone wall $[3,18]$.

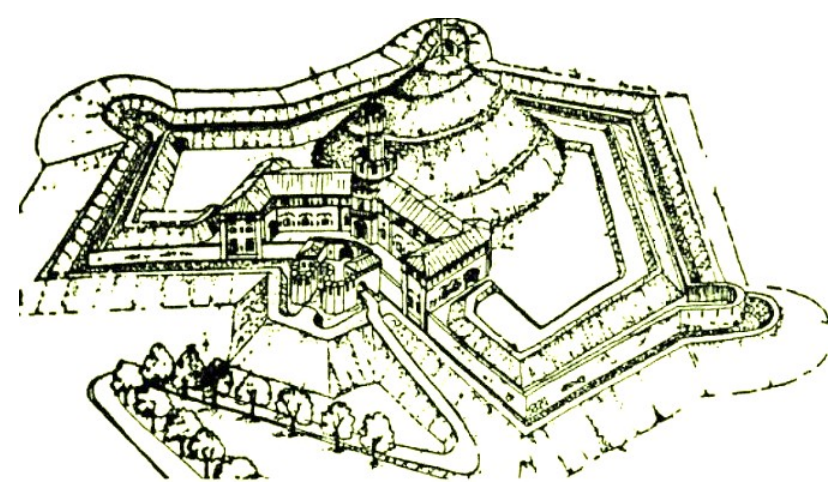

Fig. 3. Visualization of the Krakus fort.

The measurement of the mound and the area around it was made with the Leica ScanStation P40. Field work took place in very good conditions of sunny and almost windless weather. It was decided to scan from six points so that the area of mutual coverage was provided. In addition, 18 reference points in the form of frosted glass spheres were evenly distributed over the measured area, necessary in the process of linking scans from individual positions. The number of measuring points and spheres were dictated by the nature of the measured area and the need to obtain as few dead zones as possible, with simultaneous registration of the reconstructed relics of the fort wall. The scanning was carried out at a resolution of $0.05 \mathrm{~m}$ per $100 \mathrm{~m}$ both vertically and horizontally. Despite the good layout of field works, the appearance of dead zones, which are mainly located in the place of the barracks, could not be avoided. The end result of field work was obtaining six images of point clouds along with 18 images of reference spheres (Fig.4).

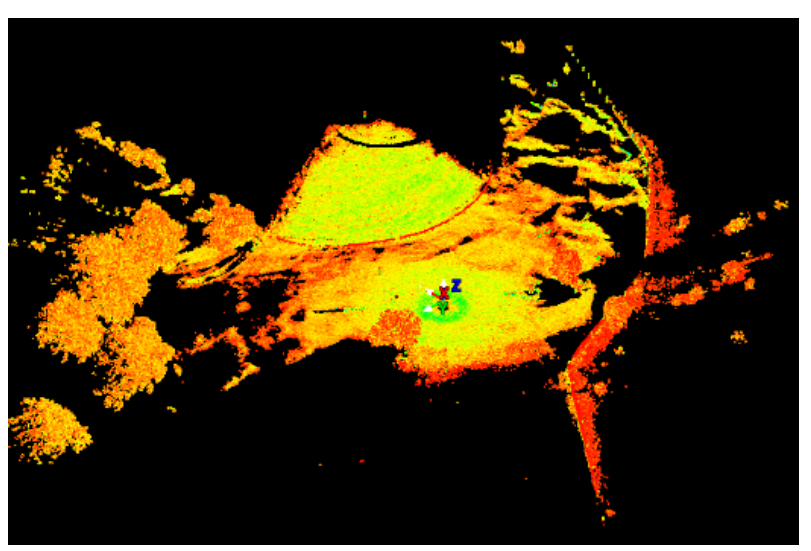

Fig. 4. An image of a single point cloud.

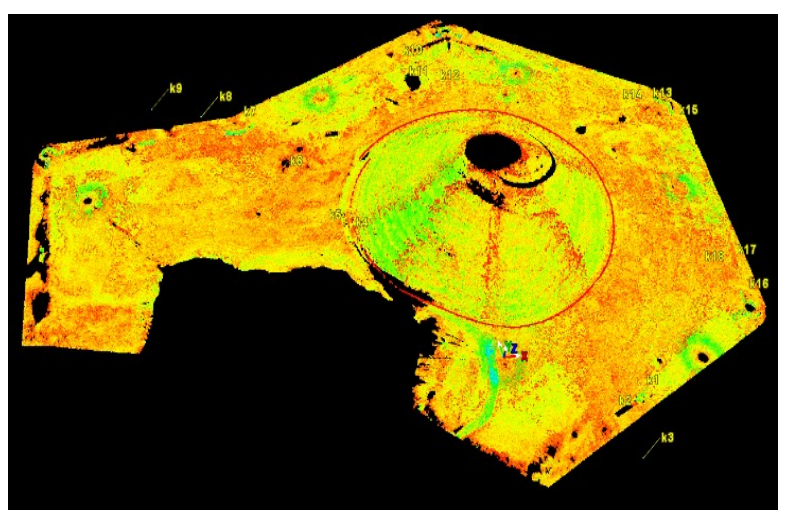

Fig.5. Point cloud after cleaning.

The point cloud post-processing was carried out in the program Leica Cyclone 3D. The first stage of the work was the orientation of scans. The orientation was performed with the accuracy of $6 \mathrm{~mm}$, however, it was necessary to exclude from the calculations three connections of clouds where the accuracy exceeded 2 $\mathrm{cm}$. The result of the orientation was the creation of a point cloud with the measurement noise, which in the further elaboration had to be removed (Fig. 5).

The next stage of the work on the point cloud was the generation of a meshgrid to obtain the terrain model being the basis for further modeling (Fig. 6).

Then modeling of the fort body was made to create a three-dimensional object at the LoD2 level, therefore, the focus was on the main elements of the fort (barracks, retaining wall, earth embankments). The dimensions of individual components of the Krakus fort were adapted to the surrounding area, using the analogy to the Kosciuszko Fort preserved to this day. The work began with modeling the wall surrounding the whole complex, because its relics have been reconstructed and could be captured during the field measurement, and what follows - they were on the terrain model. This allowed for a 
fairly precise determination of their course. The whole defensive perimeter was raised to a height of approx. $6 \mathrm{~m}$ above ground level, so that it constitutes $2 / 5$ of the height of the highest point of the fort, that is the Krakus Mound (Fig.7).

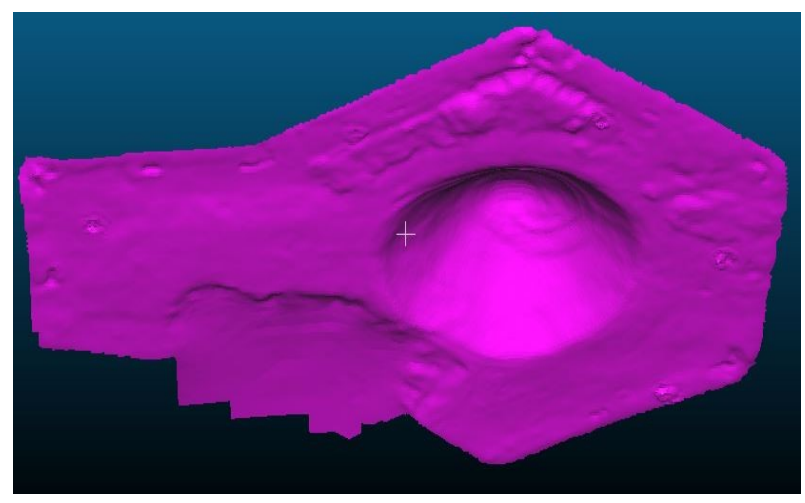

Fig. 6. Mesh generated on a point cloud.

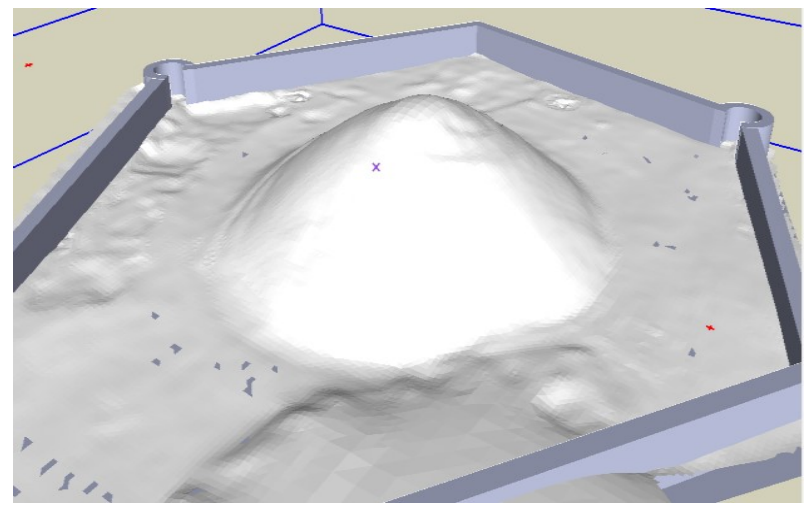

Fig. 7. Retaining wall of the Krakus fort.

The next modeled elements were the neck barracks together with the neck caponier. This fragment was so problematic because it could not be measured during the field measurement. The lack of data from this place was partially completed in the process of the mesh generation, because the CloudCompare program automatically gave this terrain the base height, elevated a few meters above the terrain model. In addition, this process allowed to determine the approximate range of the barracks in the place where the mesh height was changed. For this reason, the barracks were placed on the internal side of the wall on the whole surface of the height, on the other side, a caponier lying symmetrically between the arms of the garrison building was modeled. Such location is confirmed by archival drawings. In addition to the main body, the buildings were also enriched with a tower standing in the central part of the barracks, door and window openings and access to the entire complex (Fig.8).

The last elements of the fort model were earth embankments, the range of which could not be determined in the field. However, their course was determined in an approximate way thanks to the modeling of the retaining wall and on the basis of available sources. It was decided to place them in parallel to the wall at a distance of about $4 \mathrm{~m}$ and finish in front of the barracks, maintaining a distance of $10 \mathrm{~m}$. The front of the embankment, similarly to the archival drawings, is located slightly above the whole embankment. In addition, the embankment has been supplemented with an entry ramp located directly behind the barracks. The model has been subjected to texturing. This process involves the presentation of object surfaces using textures, that is, bitmap or procedural images $[19,20]$. It was decided to do the texturing manually. In the case of a retaining wall and the barracks, the classic building materials of Austrian fortresses in the form of brick textures and roof tiles were used, while in the case of the earth embankment, the clayey-gold color available in the palette of colors was used (Fig.9).

The last stage of the development of the object was to equip it with elements available in the Google 3D Warehouse gallery. Two types of gates placed in the caponier and in the barracks building as well as the grill in the entrance gate to the entire object were used from the available database, which undoubtedly gives the Krakus fort model the character of a real fortress (Fig.10).

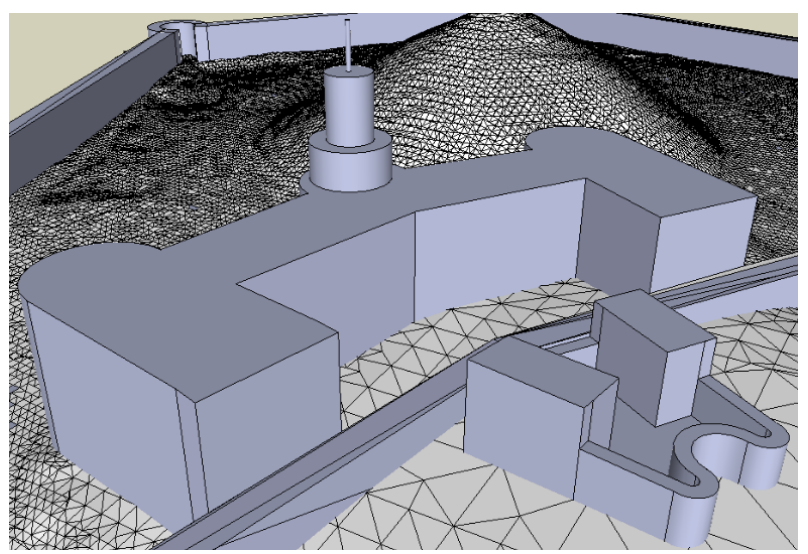

Fig. 8. Barracks and caponier neck during modeling.

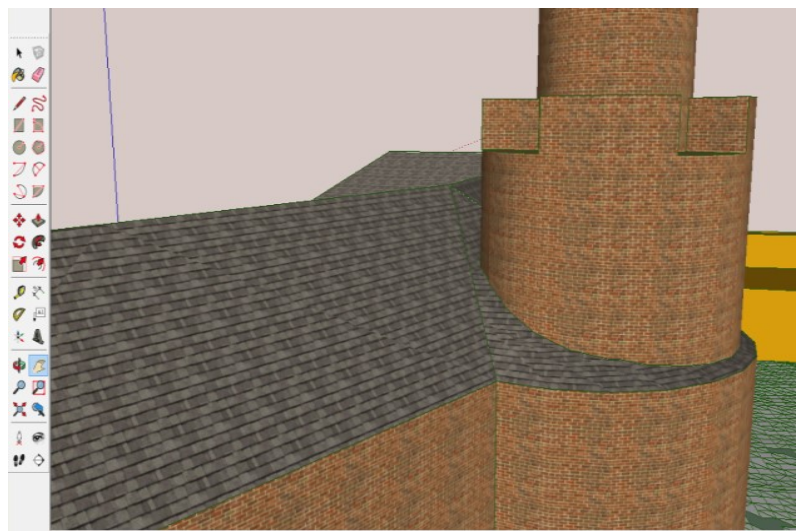

Fig. 9. Model during texturing.

After creating the model, 337 photos based on 7 designed scenes of the object view were exported from the program. The final modeling effect is shown in Figures 11-16. 


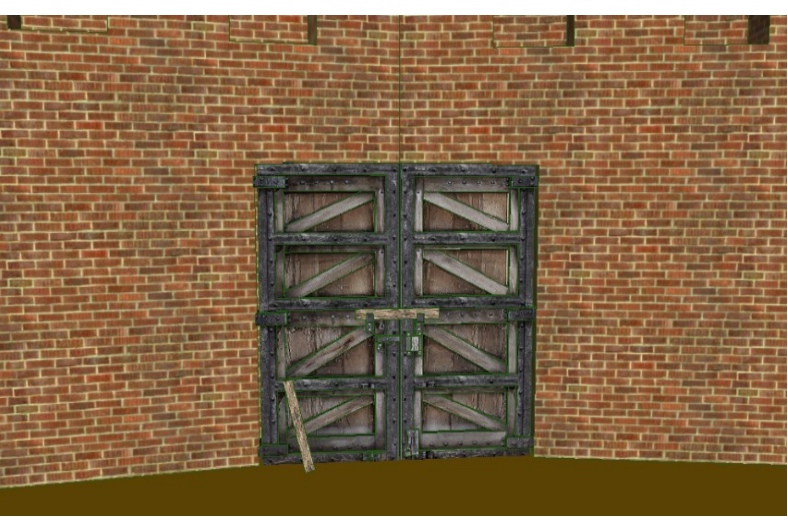

Fig. 10. Model of barracks gate.

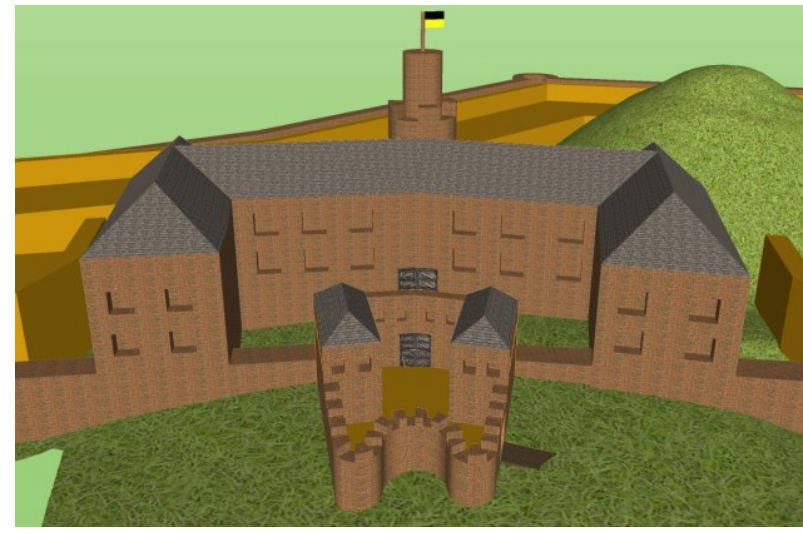

Fig. 11. The barracks of the Krakus fort - view from the north.

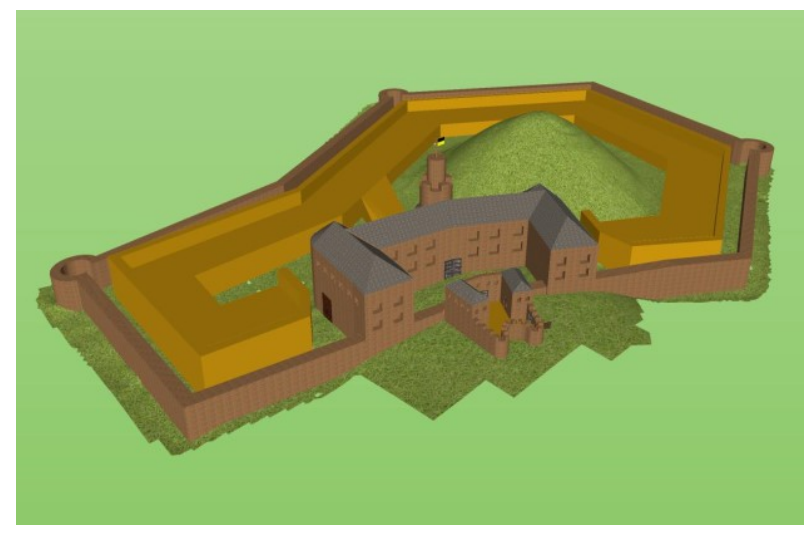

Fig. 12. Fort Krakus - isometric projection.

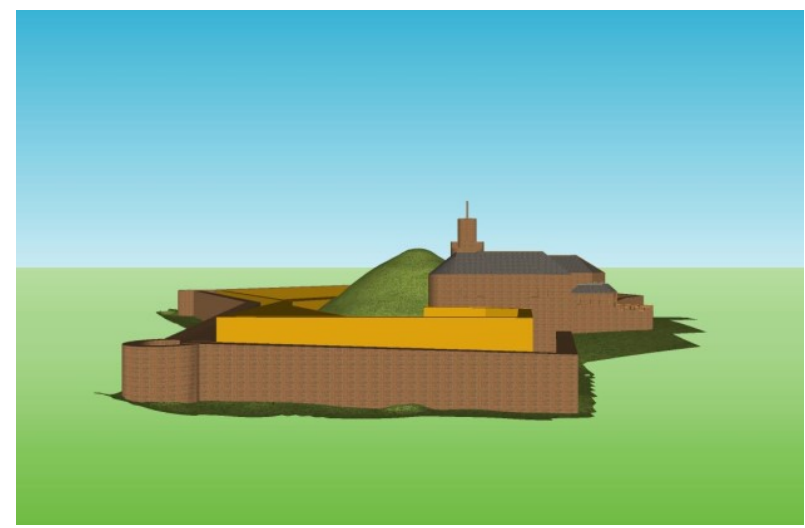

Fig. 13. Fort Krakus - view from the east.

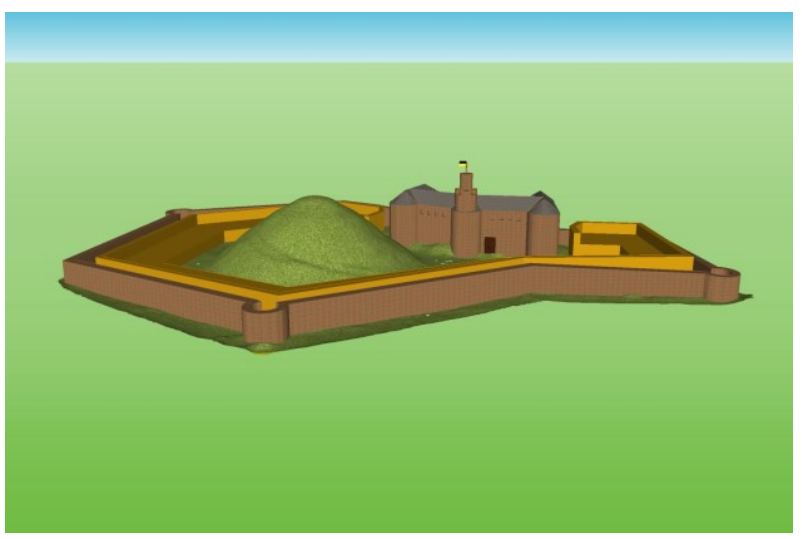

Fig. 14. Fort Krakus - view from the south.

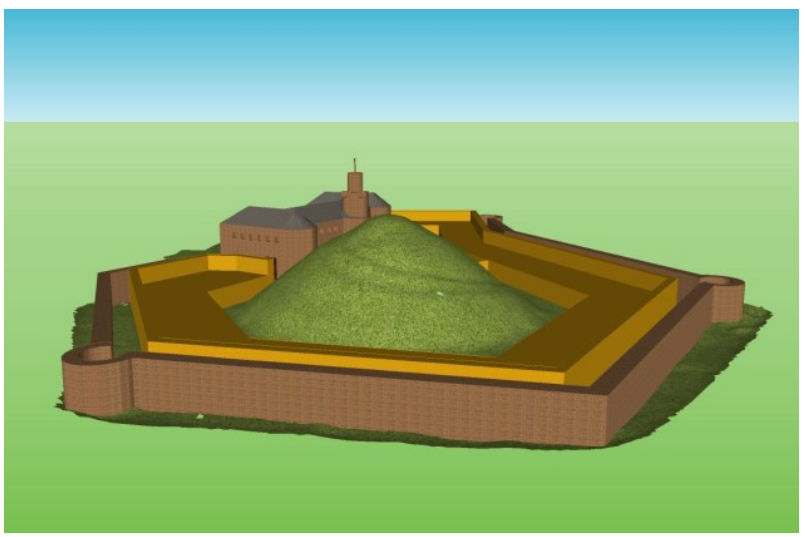

Fig. 15. Fort Krakus - view from the west.

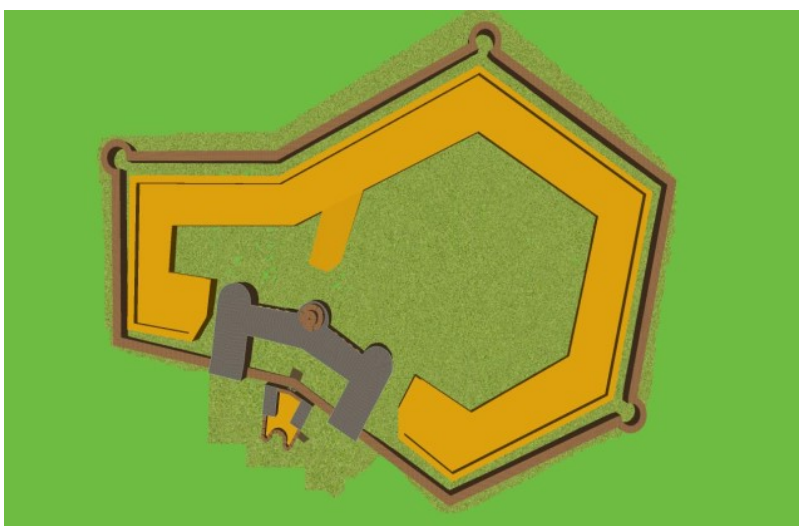

Fig. 16. Fort Krakus - view from above.

\section{Conclusions}

The desired goal of the work has been reached. The Krakus Mound and the surrounding area where once the fort was located were measured using the terrestrial scanning method. The measurement was made from six stations located around the mound with a resolution of $0.05 \mathrm{~m}$ per $100 \mathrm{~m}$. The entire surveyed area was scanned apart from the barracks site, which had a significant impact on the further course of action. The obtained data were developed in the program Leica Cyclone 3D. The edition of the point clouds included a number of activities: orientation of point clouds, clearing the composite image, unification and creation of the mesh. The orientation was made with the accuracy of $6 \mathrm{~mm}$. After unification, the grid of 
triangles was generated on the point cloud, which resulted in obtaining the terrain model. This model became the basis for further development of the architectural object - the fort modeling. Due to the small amount of archival materials, the model of the fort was created at the level of detail of LoD2. For this reason, the focus was on its most important elements, namely the retaining walls, the neck barracks with the caponier and the earth embankment. After modeling the individual elements, the surface of the blocks was covered with textures and the model was enriched with equipment elements. As a result of the performed activities, the geometrical model of the Krakus fort was obtained. Due to the field difficulties and poor archival sources, creation of the model was difficult and probably it is not a faithful reflection of how the fort looked like in reality. However, this does not change the fact that the final effect gives a good image of its appearance and can be re-used.

\section{References}

1. Z. Kurczynski, R.Preuss, Basics of photogrammetry, Oficyna Wydawnicza Politechniki Warszawskiej, Warszawa, pp. 5-9 (2000) (in polish)

2. A.Ciszewski, Elaboration of an architectural object using photogrammetric methods, Masters work. Faculty of Environmental Engineering and Land Surveying, University of Agriculture in Krakow (2018)

3. K. Becek, P. Gawronek, P. Klapa, B. Kwoczynska, P. Matula, S. Mikrut, B. Mitka, I. Piech, M. Makuch Modeling and visualization of $3 D$ data based on photogrammetric measurements and laser scanning, Monography (2015)

4. S. Al-kheder, Y. Al-shawabkeh, N. Haala, Developing a documentation system for desert palaces in Jordan using $3 D$ laser scanning and digital photogrammetry, Journal of Archaeological Science, 36, 2, pp. 537-546 (2009)

5. M. Bernat, A. Janowski, S. Rzepa, A. Sobieraj, J. Szulwic, Studies on the use of terrestrial laser scanning in the maintenance of buildings belonging to the cultural heritage, 14th SGEM GeoConference on Informatics, Geoinformatics and Remote Sensing (2014)

6. Čučaković, M. Dragović, M. Pejić, M. Srećković, J. Pandžić, The possibilities of application of $3 d$ digital models in cultural heritage objects' protection and reconstruction, ICGG Conference monGeometrija, Proceedings Belgrade (2016)

7. E. Friedli, P.W. Theiler, Documentation of Remote Archaeological Sites - A Comparison Between Long-Range Laser Scanning and UAVPhotogrammetry, FIG Congress Engaging the Challenges - Enhancing the Relevance Kuala Lumpur, Malaysia 16 - 21 June (2014)

8. H.K. Dhonju, W. Xiao, V. Sarhosis, J.P. Mills, S. Wilkinson, Z. Wang, L. Thapa, U.S. Panday,
Feasibility study of low-cost image-based heritage documentation in Nepal, The International Archives of the Photogrammetry, Remote Sensing and Spatial Information Sciences, XLII-2/W3, 3D Virtual Reconstruction and Visualization of Complex Architectures, Nafplio, Greece, pp.237-242 (2017)

9. M. Doneusa, Ch. Brieseb, M. Feraa, U. Fornwagnera, M. Griebla, M. Jannera, M. Zingerlea, Documentation and analysis of archaeological sites using aerial reconnaissance and airborne laser scanning, XXI International CIPA Symposium, 0106 October, Athens, Greece (2007)

10. Th. Kersten, M. Lindstaedt, K. Mechelke, B. Vogt, Terrestrial Laser Scanning for the Documentation of Archaeological Objects and Sites on Easter Island, Computer Applications and Quantitative Methods in Archeology - CAA'2010 Fco (2010)

11. J.L. Lerma, A.E. Seguí, M. Cabrelles, N. Haddad, S. Navarro, T. Akasheh, Integration of laser scanning and imagery for photorealistic $3 D$ architectural documentation, C.-C. Wang (Ed.) Laser Scanning, Theory and Applications, INTECH Open Access Publisher, pp. 413-430 (2011)

12. J.L. Lerma, S. Navarro, M. Cabrelles, A.E. Seguí, N. Haddad, T. Akasheh, Integration of Laser Scanning and Imagery for Photorealistic 3D Architectural Documentation, Published by World's largest Science, Technology \& Medicine Open Access book publisher, pp.413-430 (2011)

13. T.Temizer, G. Nemli, E. Ekizce, A. Ekizce, S. Demir, B. Bayram, F.H. Askin, A.V. Cobanoglu, H.F. Yilmaz, 3D documentation of a historical monument using terrestrial laser scanning case study: Byzantine water cistern, Istanbul, International Archives of the Photogrammetry, Remote Sensing and Spatial Information Sciences, Volume XL-5/W2, XXIV International CIPA Symposium, Strasbourg, France (2013)

14. B. Mitka, A. Rzonca, Integration of photogrammetric and $3 D$ laser scanning data as a flexible and effective approach for heritage documentation, 3rd ISPRS International Workshop 3D-ARCH: 3D Virtual Reconstruction and Visualization of Complex Architectures Trento, Italy, International Archives of Photogrammetry, Remote Sensing and Spatial Information Sciences, XXXVIII-5/W1 (2009)

15. A.Krooks, S. Kaasalainen, V. Kankare, M. Joensuu, P. Raumonen, M. Kaasalainen, Predicting tree structure from tree height using terrestrial laser scanning and quantitative structure models, Silva Fennica, 48, 2, article id 1125 (Online) The Finnish Society of Forest Science The Finnish Forest Research Institute.

16. M.Kędzierski, A. Fryśkowska, M. Wilińska, Terrestrial laser scanning of engineering and road objects. Biuletyn WAT, LIX, 2 (2010)

17. B Mitka, Usability of terrestrial laser scanners for the process of documentation and modeling of 
historical objects, Archiwum Fotogrametrii, Kartografii i Teledetekcji, 17b, pp. 525-534 (2007)

18. J. Bogdanowski, Fortifications and greenery of the Krakow fortress, Wydawnictwo Literackie, Kraków, pp.84-85, 90-91, 135, 253, 257 (1979)

19. J. Uchański, P. Falkowski, L. Soerensen, The problem of standardization in the field of architectural object inventory using terrestrial laser scanning techniques, Archiwum Fotogrametrii, Kartografii i Teledetekcji, 18, Międzyzdroje, pp. 633-641 (2008)

20. L.Uchański, L. Soerensen, Technology of terrestrial laser scanning in the problems of reverse engineering and analysis of dynamic processes, Archiwum Fotogrametrii, Kartografii i Teledetekcji, 21, Wrocław, pp. 415-424 (2010) 